\title{
Corrigendum: Using Crowd-Sourced Speech Data to Study Socially Constrained Variation in Nonmodal Phonation
}

\author{
Ben Gittelson ${ }^{1 *}$, Adrian Leemann ${ }^{2}$ and Fabian Tomaschek ${ }^{3}$ \\ ${ }^{1}$ Internet Institute, Oxford University, Oxford, United Kingdom, ${ }^{2}$ Center for the Study of Language and Society, University of \\ Bern, Bern, Switzerland, ${ }^{3}$ Seminar für Sprachwissenschaft, Universität Tübingen, Tübingen, Germany
}

Keywords: smartphone apps, voice quality, British English, regional variation, phonation

\section{A Corrigendum on}

Using Crowd-Sourced Speech Data to Study Socially Constrained Variation in Nonmodal Phonation

by Gittelson, B., Leemann, A., and Tomaschek, F. (2021). Front. Artif. Intell. 3:565682. doi: $10.3389 /$ frai.2020.565682

In the original article, we neglected to include the funder "Deutsche Forschungsgemeinschaft (Research Unit FOR2373 Spoken Morphology, Project Articulation of morphologically complex words), BA 3080/3-2."

In addition, a sentence was omitted from the Acknowledgments section. The section now reads:

\section{OPEN ACCESS}

Approved by:

Frontiers Editorial Office,

Frontiers Media SA, Switzerland

${ }^{*}$ Correspondence:

Ben Gittelson

ben.gittelson@gmail.com

Specialty section:

This article was submitted to

Language and Computation,

a section of the journal

Frontiers in Artificial Intelligence

Received: 07 April 2021

Accepted: 08 April 2021

Published: 19 May 2021

Citation:

Gittelson B, Leemann A and Tomaschek F (2021) Corrigendum:

Using Crowd-Sourced Speech Data

to Study Socially Constrained Variation in Nonmodal Phonation.

Front. Artif. Intell. 4:692064.

doi: 10.3389/frai.2021.692064

\section{ACKNOWLEDGMENTS}

We thank Yang $\mathrm{Li}$ and Nianheng $\mathrm{Wu}$, who provided insight and expertise that greatly assisted this research, although they may not agree with all of the interpretations and conclusions of this paper. We further wish to thank David Britain (Bern), Tam Blaxter (Cambridge), Marie-José Kolly (Republik), and Daniel Wanitsch (ibros.ch) for co-developing the English Dialects App. The app provided the dataset the current paper is based on.

Finally, we did not provide a link to the supporting data in the original Data Availability Statement. A correction has been made to the section, as seen below:

\section{DATA AVAILABILITY STATEMENT}

The data and analysis supporting the conclusions of this article can be found at https://osf.io/bvyt $2 /$.

The authors apologize for these errors and state that this does not change the scientific conclusions of the article in any way. The original article has been updated.

Copyright $(2021$ Gittelson, Leemann and Tomaschek. This is an open-access article distributed under the terms of the Creative Commons Attribution License (CC BY). The use, distribution or reproduction in other forums is permitted, provided the original author(s) and the copyright owner(s) are credited and that the original publication in this journal is cited, in accordance with accepted academic practice. No use, distribution or reproduction is permitted which does not comply with these terms. 